\title{
Mapping QTLs for phosphorus-deficiency tolerance at wheat seedling stage
}

\author{
Junying $\mathrm{Su}^{1}$, Yanmei Xiao ${ }^{1}$, Ming $\mathrm{Li}^{1}$, Quanyou $\mathrm{Liu}^{2}$, Bin Li ${ }^{1}$, Yiping Tong ${ }^{1,4}$, \\ Jizeng $\mathrm{Jia}^{3}$ \& Zhensheng $\mathrm{Li}^{1}$ \\ ${ }^{1}$ The State Key Laboratory of Plant Cell and Chromosome Engineering, Institute of Genetics and Develop- \\ mental Biology, Chinese Academy of Sciences, 100101 Beijing, China. ${ }^{2}$ Research Center for Eco-environ- \\ mental Sciences, Chinese Academy of Sciences, 100085 Beijing, China. ${ }^{3}$ Institute of Crop Science, Chinese \\ Academy of Agricultural Sciences, 100081 Beijing, China. ${ }^{4}$ Corresponding author*
}

Received 22 June 2005. Accepted in revised form 3 October 2005

Key words: QTL, Phosphorus-deficiency tolerance, SSR markers, Triticum aestivum L.

\begin{abstract}
Soil phosphorus (P) deficiency is one of the major limiting factors to crop production throughout the world. It is an important strategy to breed varieties with improved P-deficiency tolerance for sustainable agriculture. The objective of this study was to map QTLs for P-deficiency tolerance in wheat, and develop molecular marker assisted selection in breeding wheat with improved P-deficiency tolerance. A doubled haploid (DH) population, consisting of $92 \mathrm{DH}$ lines (DHLs) derived from P-deficiency tolerant wheat variety Lovrin 10 and P-deficiency sensitive variety Chinese Spring, was developed for mapping QTLs for P-deficiency tolerance. A genetic linkage map consisting of 34 linkage groups was constructed using 253 SSR markers. Shoot dry weight (SDW), tiller number (TN), shoot P uptake (SPU), and shoot P utilization efficiency (PUE) were investigated at seedling stage under P deficiency $(-\mathrm{P})$ and sufficiency $(+\mathrm{P})$ condition in two pot trials in 2002 and 2003, respectively. All traits segregated continuously in the population under either $-\mathrm{P}$ or $+\mathrm{P}$ condition. Significant positive correlations were found in between TN, SDW and SPU, whereas significant negative correlations were observed between PUE and SPU and between PUE and TN. Twenty and 19 QTLs were detected under $-\mathrm{P}$ and $+\mathrm{P}$ condition, respectively. The 39 QTLs were distributed on 21 chromosomal regions. There were three clusters of QTLs, which were associated with Xgwm25l (on chromosomes 4B), Xgwm271.2 (on chromosome 5A), and Xgwm121 (on chromosome 5D), respectively. Compared to the DHLs with all Chinese Spring alleles at the three loci, those with all Lovrin 10 alleles had, on average, much higher SPU, SDW and TN under -P condition in both trials, suggesting the importance of the three loci in controlling P-deficiency tolerance. It was interesting to find that two of the above three loci were closely linked with vernalization requirement genes $V R N-A 1$ (on chromosome $5 \mathrm{~A}$ ) and $V R N-D 1$ (on chromosome 5D). Potential implication of the linkage between P-deficiency tolerance and $V R N$ genes was discussed.
\end{abstract}

\section{Introduction}

Soil phosphorus (P) deficiency is one of the major constraints to crop production throughout the world (Schachtman et al., 1998; Vance et al., 2003). Although total $P$ in soil may be high, it is

\footnotetext{
*FAX No: +86-10-64873482.

E-mail: yptong@genetics.ac.cn
}

often present in unavailable forms or in forms that are only available outside of rhizosphere. Few unfertilized soils release $\mathrm{P}$ fast enough to meet $\mathrm{P}$ requirement of crops (Schachtman et al., 1998). Thus $P$ fertilizers are commonly applied to alleviate soil $\mathrm{P}$ deficiency. Currently, annual input of $\mathrm{P}$ fertilizers exceeds 30 million tones of $\mathrm{P}_{2} \mathrm{O}_{5}$ (http://www.fertilizer.org/ifa/), about $20 \%$ of which are applied in wheat (Triticum aestivum L.) 
(Harris, 1998). However, most of $\mathrm{P}$ applied to soil is immobilized and becomes unavailable for plant, so the recovery of applied $\mathrm{P}$ by crop plants in one growing season is often low (Holford, 1997). Therefore, developing wheat cultivars with improved ability to utilize this large soil $\mathrm{P}$ pool is very desirable, and may offer a sustainable solution to manage $\mathrm{P}$ nutrition in wheat production.

Genotypic difference for P-deficiency tolerance in wheat has been well documented (Gahoonia et al., 1999; Horst et al., 1993; Li et al., 1995; Manske et al., 2000, 2001; Osborne and Rengel, 2002; Ozturk et al., 2005), indicating that it is possible to improve P-deficiency tolerance of wheat through genetic approach. However, the genetic basis of P-deficiency tolerance in wheat is still not understood well. There is ample evidence indicating that plant P-deficiency tolerance is controlled by polygenes. QTLs for P-deficiency tolerance and related traits have been successfully studied in rice (Oryza sativa L.), maize (Zea mays L.), common bean (Phaseolus vulgaris L.), and soybean (Glycine max L. Merr.) (Li et al., 2005; Liao et al., 2004; Ming et al., 2000; Ni et al., 1998; Wissuwa et al., 1998, Yan et al., 2004; Zhu et al., 2005). Using a set of nulli-tetrasominc lines, which are derived from common wheat variety Chinese Spring, chromosomes 1A, 4A, 7A, 3B, 5B and 7D have been deduced to be involved in P-deficiency tolerance ( $\mathrm{Li}$ et al., 1999a). In wheat relatives, chromosomes $1 \mathrm{R}, 2 \mathrm{R}$ and $7 \mathrm{R}$ of rye (Secale cereale L.) and chromosomes $4 \mathrm{E}$ and $6 \mathrm{E}$ of Thinopyrum ponticum have been reported to carry P-deficiency tolerant genes (Li et al., 1999b, Liu et al., 2001). However, report on QTLs for P-deficiency tolerance in wheat is still lacking.

$\mathrm{P}$ nutrition status in early growing season is critical for crop production. $\mathrm{P}$ deficiency during the first 4-6 weeks of growth causes large reductions in tiller development and head formation of wheat and barley, which can not be recovered even if sufficient $P$ is supplied at a later stage (Brenchley, 1929; Gericke, 1924, 1925). Therefore, understanding the genetic control of P-deficiency tolerance at seedling stage is very important and relevant to development of $\mathrm{P}$ efficient varieties. The objective of this study was to detect QTLs for tiller number (TN), shoot dry weight (SDW), shoot P uptake (SPU), and shoot $\mathrm{P}$ utilization efficiency (PUE) under P-deficiency or sufficiency condition. In the following sections the results of our study were described, together with discussions on genetic control of P-deficiency tolerance at wheat seedling stage.

\section{Materials and methods}

\section{Plant materials}

A double haploid (DH) population consisting of 150 lines was developed using F1 hybrid between Lovrin 10 (P-deficiency tolerant) and Chinese Spring (P-deficiency sensitive) through anther culture (Ouyang et al., 1973). Ninety-two DHLs, randomly selected from the original 150 lines, were used for phenotypic analysis and construction of genetic linkage map.

\section{Evaluation of plant performance}

Two independent pot trials at seedling stage were carried out in 2002 and 2003, respectively. The soil used in the pot trials was calcareous and was collected from the experimental station of Institute of Genetics and Developmental Biology (IGDB), Chinese Academy of Sciences (CAS) in Beijing. The total $\mathrm{P}$ and available $\mathrm{P}$ (Olsen-P) in the soil were 884 and $8 \mathrm{mg} \mathrm{kg}^{-1}$, respectively. The first trial (trial 1) was carried out from October 14 to December 4 in 2002, and the second one (trial 2) was from October 21 to December 30 in 2003. Each trial consisted of two treatments $[\mathrm{P}$ deficiency $(-\mathrm{P})$ and $\mathrm{P}$ sufficiency $(+\mathrm{P})]$ with three replications each. The soil for the $+\mathrm{P}$ treatment was given $75 \mathrm{mg} \mathrm{kg}^{-1}$ of $\mathrm{N}$ (as urea) and $25 \mathrm{mg} \mathrm{kg}^{-1}$ of $\mathrm{K}$ and $20 \mathrm{mg} \mathrm{kg}^{-1}$ of $\mathrm{P}$ (as potassium dihydrogen phosphate). The soil for the $-\mathrm{P}$ treatment was provided with the same amounts of $\mathrm{N}$ (as urea) and $\mathrm{K}$ (as potassium chloride) but not P. Seeds of the 92 DHLs and their parents were germinated at $25^{\circ} \mathrm{C}$ for 2 days. Six germinated seedlings were planted in each plastic pot (with $2.5 \mathrm{~kg}$ air-dried soil), and were thinned to 5 plants per pot at three-leaf stage.

The pots were randomly placed in a glasshouse. Their positions were changed every week. During the experimental periods, the day's lowest temperature in the glasshouse ranged from 2 to $8{ }^{\circ} \mathrm{C}$, and the day's highest temperature varied 
from 20 to $30{ }^{\circ} \mathrm{C}$. Tiller number was investigated just before harvest. The aerial parts of plant were harvested after grown in the glasshouse for 7 weeks in trial 1 , and 10 weeks in trial 2 . The plant samples were oven-dried at $65^{\circ} \mathrm{C}$ for 3 days for measuring shoot dry weight and total $P$ concentration. The dried samples were milled and subsequently digested with concentrated $\mathrm{H}_{2} \mathrm{SO}_{4}$ and $\mathrm{H}_{2} \mathrm{O}_{2}$ for determining total $\mathrm{P}$ using molybdate-blue colorimetric method (Murphy and Riley, 1962).

The following traits were evaluated: (1) tiller number per plant (TN), (2) shoot dry weight per plant (SDW), (3) shoot P uptake per plant (SPU, value of shoot dry weight $\times$ total $\mathrm{P}$ concentration) and (4) shoot $\mathrm{P}$ utilization efficiency (PUE, SDW produced by unit SPU). Variance and correlation analyses were conducted using SPSS11.0 for Windows.

\section{Construction of genetic linkage map}

Genetic map was constructed using wheat microsatellites (SSR) markers. Genomic DNA samples from 92 DHLs and their parents were isolated using CTAB method (Murray and Thompson, 1980). A total of 450 SSR primer sets, developed by Röder et al. (1998, prefix: gwm), Pestsova et al. (2000, prefix: gdm), and International Wheat Microsatellite Consortium (prefix: wmc), was tested on Lovrin 10 and Chinese Spring. There were 217 sets showing polymorphisms. The polymorphic primer sets were then used to analyze the genotypes of DHLs. Amplified fragments were separated on $6 \%(\mathrm{w} / \mathrm{v})$ denaturing polyacrylamide gels and were detected by silver staining. The genetic map was constructed using MAPMAKER EXP 3.0 (Lander and Botstein, 1989), and map distance (cM) was derived based on Kosambi function (Kosambi, 1944).

\section{Detection of $Q T L S$}

QTL detection was conducted by composite interval mapping (Zeng, 1994). Analyses of QTL location, origin of positive alleles, and additive values of QTLs were performed using QTL Cartographer version 2.0 (Model 6, Basten et al., 2001). Forward regression was analyzed using a window size of $10 \mathrm{cM}$, a walk speed of $1 \mathrm{cM}$ and five control markers. Threshold for detection of putative QTL $(P<0.05)$ was estimated by 1000 permutations.

\section{Results}

\section{Construction of genetic linkage map}

The 217 polymorphic primer sets produced 260 loci, of which 253 markers were assigned to 34 linkage groups at LOD $>3$ based on the linkage to anchor markers (gwm, Röder et al., 1998) (Figure 1). The linkage map covered $2182.8 \mathrm{cM}$ genetic distance and the average interval size was $8.6 \mathrm{cM}$. The map lengths of genomes A, B and D were $890.3,764.5$ and $528.0 \mathrm{cM}$, respectively. The segregation ratio of most markers followed the Mendelian ratio (1:1). Fifty-six markers $(22 \%$ of total) deviated from the segregation ratio, of which 31 were biased towards Lovrin 10 and 25 towards Chinese Spring. In general, the mapping orders of the SSR markers detected in this work were in good agreement with those reported previously (Röder et al., 1998; Pestsova et al., 2000), indicating that the linkage map constructed was suitable for QTL mapping.

\section{Evaluation of phenotypes}

In both trials, significant differences were observed for all four traits among the tested lines (92 DHLs and two parents) and between the two $\mathrm{P}$ treatments (Table 1). The interactions between genotype and $\mathrm{P}$ level were significant for all four traits (Table 1).

The female parent Lovrin 10 was more tolerant to $\mathrm{P}$ deficiency than the male parent Chinese Spring. Compared to Chinese Spring, Lovrin 10 developed more $\mathrm{TN}$ in both $\mathrm{P}$ treatments in both trials, produced higher SDW in both $\mathrm{P}$ treatments in trial 1 , and had higher relative values $(-\mathrm{P} /+\mathrm{P})$ of $\mathrm{SDW}$ or $\mathrm{TN}$ in both trials (Table 2). Furthermore, Lovrin 10 had higher SPU than Chinese Spring in both treatments in both trials. However, Chinese Spring exhibited higher PUE in both $\mathrm{P}$ treatments in both trials, indicating that this variety might use internal $\mathrm{P}$ more efficiently than Lovrin 10 (Table 2). SDW, TN and SPU in trial 2 were higher than the corresponding values in trial 1 , this might be related to the fact that the plants 


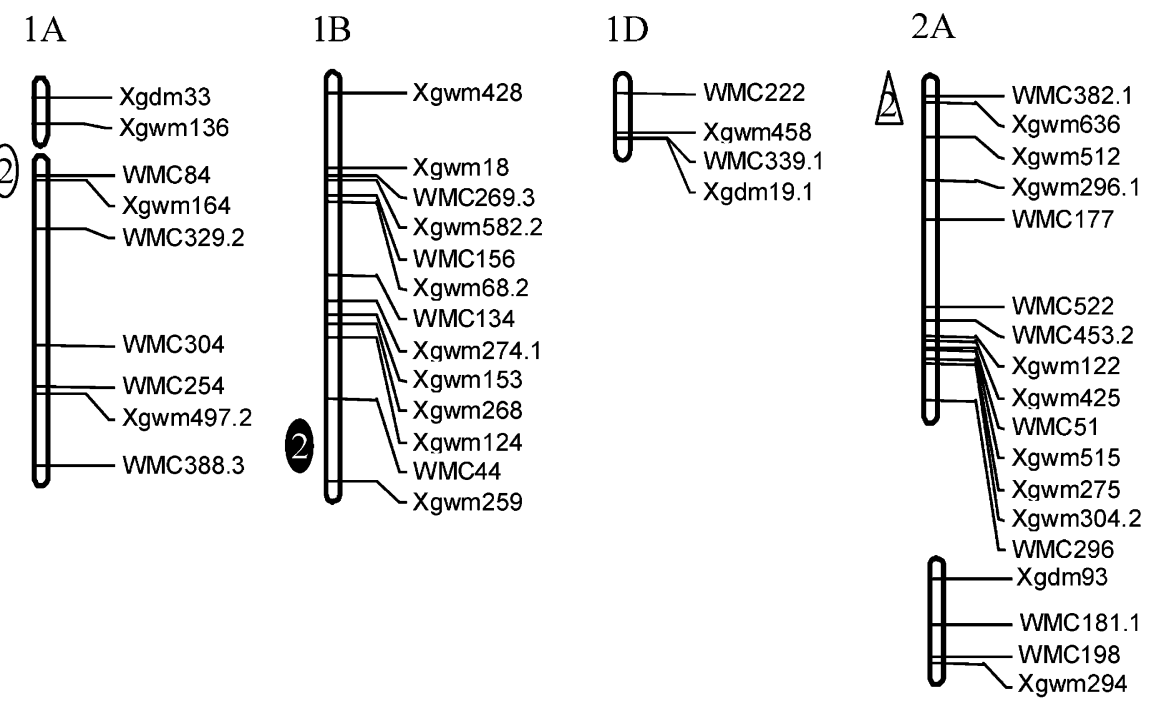

2B

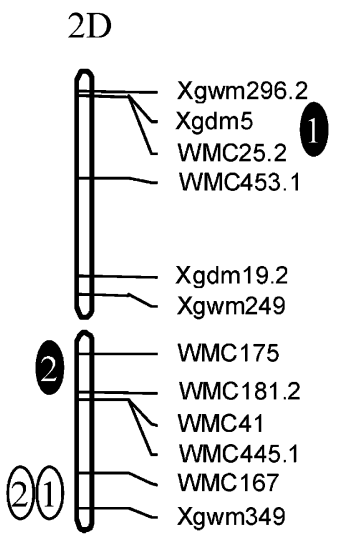

$3 \mathrm{~A}$

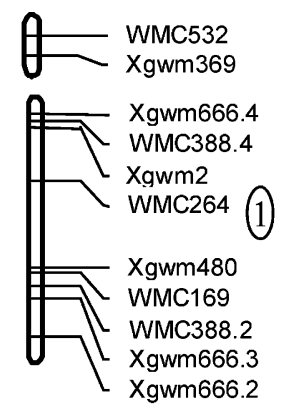

$3 B$

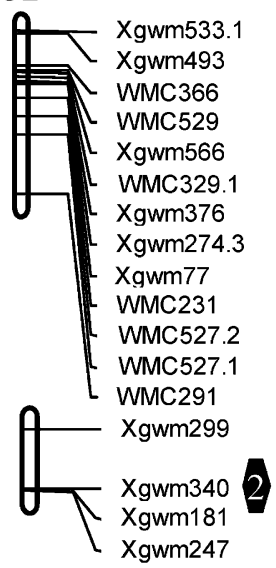

$3 \mathrm{D}$

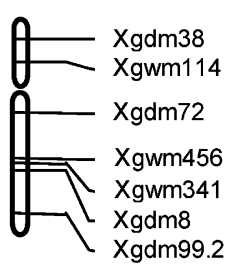

$4 \mathrm{~A}$

4B

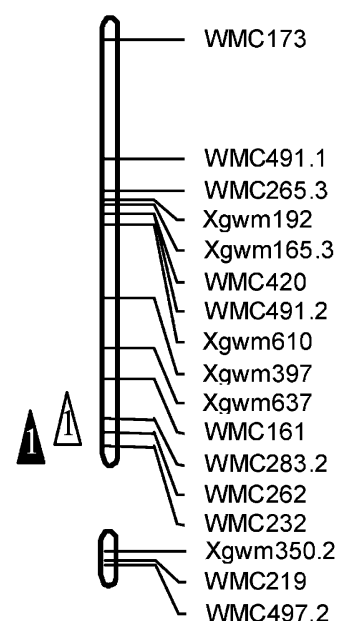

4D
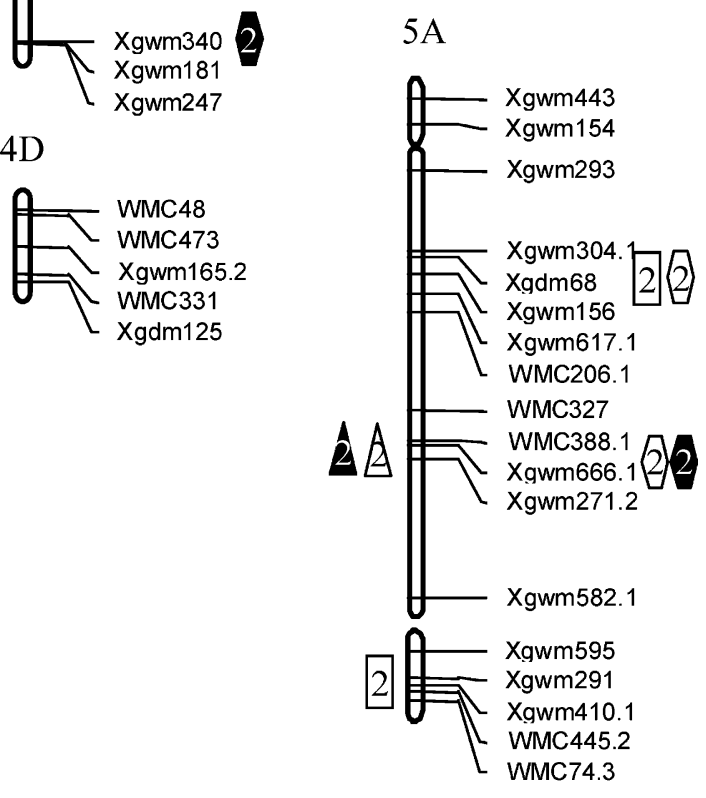

Figure 1. Genetic map and QTLs for investigated traits under $-\mathrm{P}$ and $+\mathrm{P}$ conditions in the two pot trials. The numbers 1 and 2 in the legends indicate QTLs detected in trials 1 and 2, respectively. QTLs with Lovrin 10 and Chinese Spring alleles are listed on the left and the right of the chromosomes, respectively. 


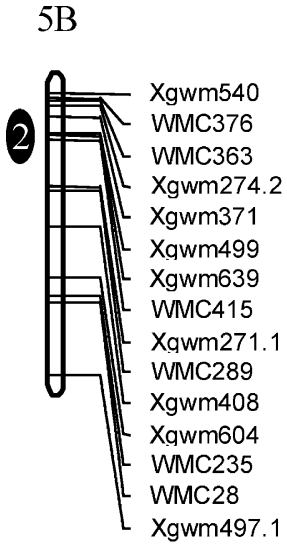

$6 \mathrm{D}$

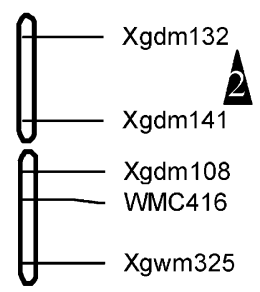

5D

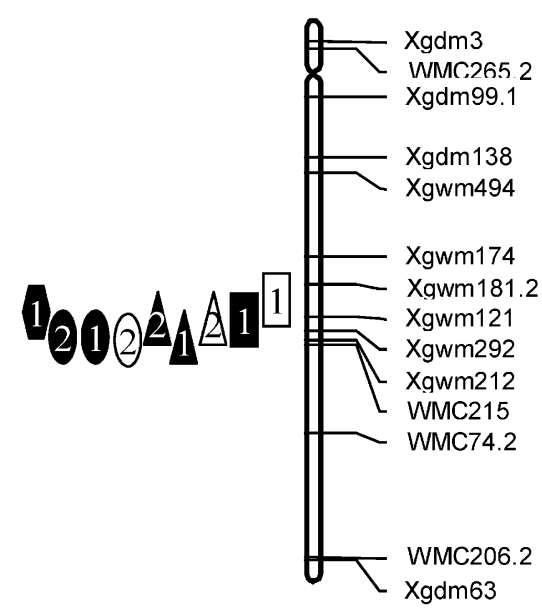

$6 \mathrm{~A}$

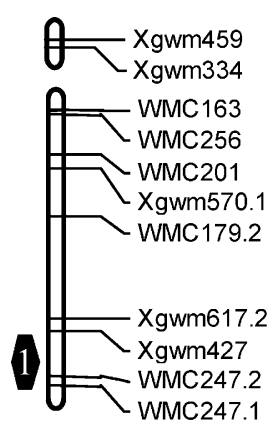

$6 \mathrm{~B}$

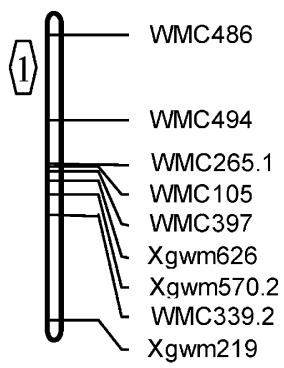

$7 \mathrm{D}$

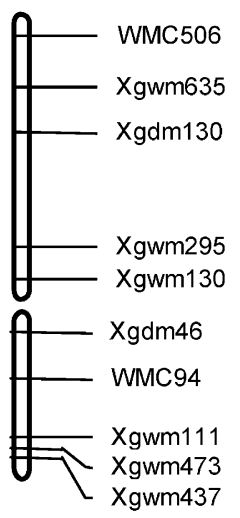

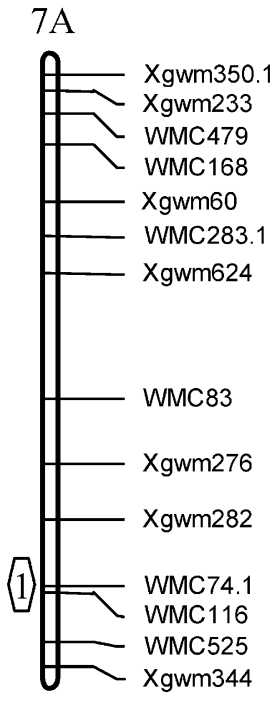

$7 \mathrm{~B}$

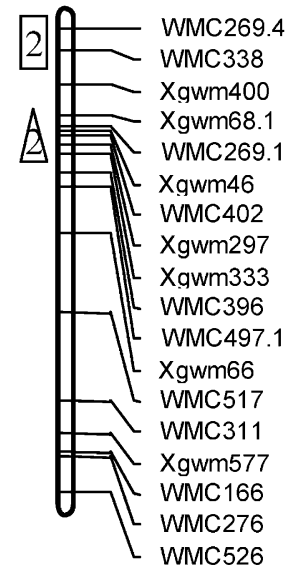

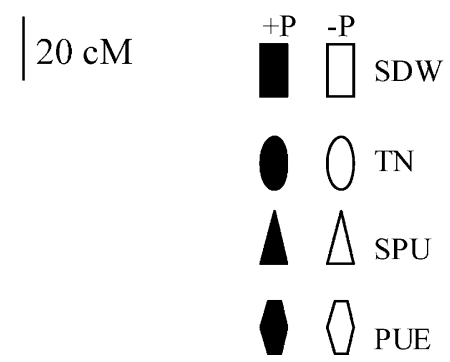

Figure 1. Continued.

were grown 3 weeks longer in trial 2. Comparative analyses of phenotypic variations revealed that all four traits segregated continuously in the $\mathrm{DH}$ population. For all four traits, there existed DHLs with values that were higher or lower than both parents, indicating potential transgressive variations and the presence of positive and negative alleles in both parents. 
Table 1. Analysis of variance for the four traits investigated in two pot trials

\begin{tabular}{|c|c|c|c|c|c|}
\hline & & \multicolumn{2}{|l|}{ Trial 1} & \multicolumn{2}{|l|}{ Trial 2} \\
\hline & & $F$ value & $P$ value & $F$ value & $P$ value \\
\hline \multirow[t]{3}{*}{$\mathrm{TN}$} & P levels & 2430.5 & $<0.001$ & 435.7 & $<0.001$ \\
\hline & Genotypes & 31.7 & $<0.001$ & 53.9 & $<0.001$ \\
\hline & P level $\times$ Genotype & 2.7 & $<0.001$ & 2.5 & $<0.001$ \\
\hline \multirow[t]{3}{*}{ SDW } & $\mathrm{P}$ levels & 2325.8 & $<0.001$ & 146.0 & $<0.001$ \\
\hline & Genotypes & 21.5 & $<0.001$ & 13.5 & $<0.001$ \\
\hline & P level $\times$ Genotype & 3.6 & $<0.001$ & 1.45 & $<0.01$ \\
\hline \multirow[t]{3}{*}{ SPU } & P levels & 4761.1 & $<0.001$ & 1861.7 & $<0.001$ \\
\hline & Genotypes & 13.3 & $<0.001$ & 7.4 & $<0.001$ \\
\hline & P level $\times$ Genotype & 4.7 & $<0.001$ & 1.7 & $<0.001$ \\
\hline \multirow[t]{3}{*}{ PUE } & P levels & 3036.4 & $<0.001$ & 2064.8 & $<0.001$ \\
\hline & Genotypes & 11.2 & $<0.001$ & 14.0 & $<0.001$ \\
\hline & P level $\times$ Genotype & 3.2 & $<0.001$ & 2.6 & $<0.001$ \\
\hline
\end{tabular}

SDW, shoot dry weight (g plant $\left.{ }^{-1}\right)$; TN, tiller numbers per plant; SPU, shoot $\mathrm{P}$ uptake per plant (mg plant ${ }^{-1}$ ); PUE, shoot P utilization efficiency $\left(\mathrm{g} \mathrm{SDW} \mathrm{g}^{-1} \mathrm{P}\right)$.

Table 2. Mean values and ranges for the four traits in the $\mathrm{DH}$ population and the parents

\begin{tabular}{|c|c|c|c|c|c|c|c|c|c|c|}
\hline \multirow[t]{3}{*}{ Traits } & \multirow[t]{3}{*}{ Trial } & \multicolumn{6}{|l|}{ Parents } & \multicolumn{3}{|l|}{ DHLs } \\
\hline & & \multicolumn{3}{|c|}{ Lovrin 10} & \multicolumn{3}{|c|}{ Chinese Spring } & \multicolumn{3}{|c|}{ Mean (minimum to maximum values) } \\
\hline & & $-\mathrm{P}$ & $+\mathrm{P}$ & $-\mathrm{P} /+\mathrm{P}$ & $-\mathrm{P}$ & $+\mathrm{P}$ & $-\mathrm{P} /+\mathrm{P}$ & $-\mathrm{P}$ & $+\mathrm{P}$ & $-\mathrm{P} /+\mathrm{P}$ \\
\hline $\mathrm{TN}$ & 1 & 2.6 & 3.6 & 72.3 & 1.1 & 2.6 & 42.6 & $1.8(1.0-3.8)$ & $3.1(1.4-5.3)$ & $58.7(33.7-90.7)$ \\
\hline$\left(\right.$ tillers plant $\left.{ }^{-1}\right)$ & 2 & 6.0 & 7.4 & 81.0 & 3.2 & 4.6 & 70.0 & $4.0(1.5-8.0)$ & $5.0(2.0-9.3)$ & $81.0(52.9-113.0)$ \\
\hline SDW & 1 & 0.14 & 0.22 & 65.5 & 0.08 & 0.15 & 49.2 & $0.12(0.05-0.19)$ & $0.21(0.09-0.32)$ & $59.6(37.5-93.6)$ \\
\hline$\left(\right.$ g plant $\left.^{-1}\right)$ & 2 & 0.44 & 0.49 & 90.0 & 0.46 & 0.58 & 79.3 & $0.53(0.37-0.74)$ & $0.59(0.43-0.85)$ & $91.0(70.0-113.0)$ \\
\hline SPU & 1 & 0.25 & 0.59 & 42.4 & 0.11 & 0.36 & 30.1 & $0.18(0.05-0.32)$ & $0.51(0.23-0.82)$ & $36.4(17.0-65.2)$ \\
\hline$\left(\mathrm{mg} \mathrm{plant} \mathrm{t}^{-1}\right)$ & 2 & 0.92 & 1.62 & 56.4 & 0.50 & 1.14 & 43.8 & $0.78(0.43-1.13)$ & $1.35(0.77-2.17)$ & $58.2(30.3-80.3)$ \\
\hline PUE & 1 & 583 & 376 & 155 & 728 & 442 & 165 & $689(484-1132)$ & $413(3112-592)$ & $168(127-274)$ \\
\hline$\left(\mathrm{g} \mathrm{SDW} \mathrm{g}^{-1} \mathrm{P}\right)$ & 2 & 482 & 302 & 160 & 916 & 512 & 179 & $702(371-1065)$ & $445(239-778)$ & $159(125-267)$ \\
\hline
\end{tabular}

SPU was more seriously reduced by $\mathrm{P}$ deficiency than the other three traits (Table 2). On average, the relative SPU $(-\mathrm{P} /+\mathrm{P})$ of DHLs was $36.4 \%$ in trial 1 and $58.2 \%$ in trial 2 , much lower than the average relative $\mathrm{TN}(58.7 \%$ in trial 1 and $81.0 \%$ in trial 2 ) and the average relative SDW (59.6\% in trial 1 and $91.0 \%$ in trial 2) (Table 2). However, PUE was generally much higher in $-\mathrm{P}$ treatment (Table 2).

Both positive and negative correlations were observed in between the four traits (Table 3). SDW was generally positively correlated with SPU and PUE under both $P$ levels in both trials (Table 3). SDW was positively correlated with TN under both P levels only in trial 1 (Table 3).
The poor correlation between $\mathrm{TN}$ and SDW in trial 2 was possibly caused by the relative longer growth period of the trial 2, which was favorable for the growth of spring DHLs that generally had fewer but larger tillers than winter DHLs. TN was positively correlated with SPU, but negatively or poorly with PUE (Table 3 ). Furthermore, it was found that SPU in $-\mathrm{P}$ treatment was significantly and positively correlated with relative SDW $[r=0.35(P<0.01)$ in trial 1 and $0.32(P<0.01)$ in trial 2] and relative $\mathrm{TN}$ $[r=0.23 \quad(P<0.05)$ in trial 1 and 0.42 $(P<0.01)$ in trial 2]. However, PUE in $-\mathrm{P}$ treatment was negatively or poorly correlated with relative SDW and TN (data not shown). 
Table 3. Correlation coefficients between investigated traits

\begin{tabular}{|c|c|c|c|c|c|c|}
\hline \multirow[t]{2}{*}{ Traits pair } & \multicolumn{3}{|l|}{ Trial 1} & \multicolumn{3}{|l|}{ Trial 2} \\
\hline & $-\mathrm{P}$ & $+\mathrm{P}$ & $-\mathrm{P} /+\mathrm{P}$ & $-\mathrm{P}$ & $+\mathrm{P}$ & $-\mathrm{P} /+\mathrm{P}$ \\
\hline TN vs. SDW & $0.43 * *$ & $0.55^{* *}$ & $0.32 * *$ & 0.08 & 0.05 & $0.33 * *$ \\
\hline TN vs. SPU & $0.54 * *$ & $0.54 * *$ & $0.34 * *$ & $0.63 * *$ & $0.62 * *$ & $0.41 * *$ \\
\hline TN vs. PUE & $-0.22^{*}$ & 0.01 & -0.17 & $-0.51 * *$ & $-0.54 * *$ & $-0.21 *$ \\
\hline SDW vs. SPU & $0.82 * *$ & $0.84 * *$ & $0.81 * *$ & $0.32 * *$ & $0.27 *$ & $0.53 * *$ \\
\hline SDW vs. PUE & 0.19 & $0.29 * *$ & -0.04 & $0.45 * *$ & $0.42 * *$ & 0.13 \\
\hline SPU vs. PUE & $-0.35^{* *}$ & $-0.24^{*}$ & $-0.51^{* *}$ & $-0.68 * *$ & $-0.73 * *$ & $-0.74 * *$ \\
\hline
\end{tabular}

$* P<0.05, * * P<0.01$.

Significant and positive correlations between trials were observed for all traits. The correlation coefficients for TN between trials 1 and 2 were $0.69(P<0.01)$ under $-\mathrm{P}$ condition and 0.70 $(P<0.01)$ under $+\mathrm{P}$ condition, reflecting high heredity of TN. The correlation coefficients for SDW, SPU or PUE between the two trials were relatively low [from $0.25(P<0.05)$ to 0.53 $(P<0.01)$ in $-\mathrm{P}$ treatment, and from 0.40 $(P<0.01)$ to $0.45(P<0.01)$ under $+\mathrm{P}$ condition], indicating that these three traits were susceptible to environmental influence.

\section{Detection of QTLS}

The absolute values of the four traits were used to map QTLs. The threshold LOD values ranged from 3.00 to 3.25 for the four traits in 1000 permutation tests, and the threshold LOD value 3.25 was used to declare the presence of putative QTLs. A total of 39 QTLs was detected for the four traits and mapped to 16 chromosomes (Table 4, Figure 1). Thirty QTLs had positive alleles from the P-deficiency tolerant parent Lovrin 10. Interestingly, nine QTLs containing positive alleles, most of which concerned PUE, were also found in the P-deficiency sensitive parent Chinese Spring. Thirty-one QTLs were found to have VE (percentage of phenotypic variation explained by a QTL) $<20 \%$, and were thus designated as minor QTLs. By contrast, the VE of eight QTLs exceeded $20 \%$, and they were considered as major QTLs.

For TN, two major and four minor QTLs were discovered under $-\mathrm{P}$ condition. The two major QTLs were located on chromosomes 4B and $5 \mathrm{D}$, respectively, both of which were contributed by Lovrin 10 . Under $+\mathrm{P}$ condition, one major and seven minor QTLs were detected for TN. The major QTL, located on chromosome $5 \mathrm{D}$ and possessed a VE value of $34.6 \%$, was the most significant QTL detected in this study. For SDW, four minor QTLs were detected under -P condition whereas only a single major QTL was found under $+\mathrm{P}$ condition. The major QTL found under $+\mathrm{P}$ condition was located on chromosome 5D (Table 4). A total of 11 QTLs was discovered to control SPU, six (one major and five minor QTLs) were revealed under $-\mathrm{P}$ condition and five (one major and 4 minor QTLs) were detected under $+\mathrm{P}$ condition. The two major QTLs, co-localized on chromosome 5D, were contributed by Lovrin 10. For PUE, one major and three minor QTLs were detected under -P condition, and one major and four minor QTLs were found under $+\mathrm{P}$ condition. The major QTL under $-\mathrm{P}$ condition was flanked with markers $X g d m 68$ and $X g w m 156$ on chromosome 5A, whereas the major QTL under $+\mathrm{P}$ condition was located on chromosome 3B.

From the above data, it was clear that there were five major QTLs on chromosome 5D. The five major QTLs, controlling related traits (TN, SDW, SPU), were all distributed around the SSR marker Xgwm121 (Figure 1). Besides the major QTLs, four minor QTLs (controlling TN, SPU and PUE under $+\mathrm{P}$ condition, and SDW under $-\mathrm{P}$ condition in trial 1) were also mapped at this locus (Table 4 and Figure 1). This locus contained the most significant QTL for TN, SDW and SPU detected in this study under either $-\mathrm{P}$ or $+\mathrm{P}$ condition (Table 4 ), they were all contributed by Lovrin 10 (Table 4). Based on Xgwm121 genotypes, the 92 DHLs were divided into two genotypic groups. The one carrying the Lovrin 10 allele had, in general, substantially higher TN, 
Table 4. QTLs detected under P deficiency and sufficiency conditions in the two pot trials

\begin{tabular}{|c|c|c|c|c|c|c|c|}
\hline Trait & Treatment & Trial & $\mathrm{Chr}^{\mathrm{a}}$ & Marker Interval $^{\mathrm{b}}$ & LOD & $\operatorname{VE}(\%)^{\mathrm{c}}$ & $\mathrm{ADD}^{\mathrm{d}}$ \\
\hline $\mathrm{TN}$ & \multirow[t]{6}{*}{$-\mathrm{P}$} & 2 & $1 \mathrm{~A}$ & WMC84-Xgwm164 & 3.5 & 7.2 & -0.4 \\
\hline \multirow[t]{13}{*}{ (tillers plant $t^{-1}$ ) } & & 2 & $2 \mathrm{D}$ & WMC167-Xgwm349 & 4.6 & 11.4 & -0.6 \\
\hline & & 1 & $2 \mathrm{D}$ & WMC167- $\overline{\text { Xgwm349 }}$ & 3.3 & 9.5 & -0.2 \\
\hline & & 1 & $3 \mathrm{~A}$ & WMC264- $\overline{\mathrm{Xgwm} 480}$ & 4.7 & 19.8 & 0.3 \\
\hline & & 1 & $4 \mathrm{~B}$ & Xgwm251-Xgwm6 & 4.9 & 21.8 & -0.3 \\
\hline & & 2 & $5 \mathrm{D}$ & Xgwm292-Xgwm212 & 11.5 & 28.7 & -0.9 \\
\hline & \multirow[t]{8}{*}{$+\mathrm{P}$} & 2 & $1 \mathrm{~B}$ & WMC44-Xgwm259 & 7.6 & 11.4 & -0.7 \\
\hline & & 2 & $2 \mathrm{D}$ & $\overline{\mathrm{WMC17}} 5-\mathrm{WMC} 181.2$ & 9.5 & 17.2 & -0.8 \\
\hline & & 1 & $2 \mathrm{D}$ & WMC25.2-WMC453.1 & 3.6 & 13.9 & 0.3 \\
\hline & & 2 & $4 \mathrm{~B}$ & $\overline{\text { Xgwm251-Xgwm6 }}$ & 3.5 & 7.7 & -0.6 \\
\hline & & 1 & $4 \mathrm{~B}$ & $\overline{\mathrm{Xgwm} 251}$-Xgwm6 & 3.3 & 11.8 & -0.3 \\
\hline & & 2 & $5 \mathrm{~B}$ & $\overline{\text { Xgwm371-Xgwm499 }}$ & 3.9 & 5.7 & -0.5 \\
\hline & & 2 & $5 \mathrm{D}$ & Xgwm292-Xgwm212 & 17.9 & 34.6 & -2.0 \\
\hline & & 1 & $5 \mathrm{D}$ & 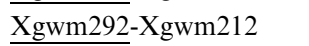 & 7.0 & 17.9 & -0.4 \\
\hline \multirow{5}{*}{$\begin{array}{l}\text { SDW } \\
\left(\text { g plant }^{-1}\right)\end{array}$} & \multirow[t]{4}{*}{$-\mathrm{P}$} & 2 & $5 \mathrm{~A}$ & $\overline{\text { Xgdm68-Xgwm156 }}$ & 4.0 & 12.2 & 0.03 \\
\hline & & 2 & $5 \mathrm{~A}$ & Xgwm291-Xgwm410.1 & 4.5 & 13.9 & -0.03 \\
\hline & & 1 & $5 \mathrm{D}$ & $\mathrm{Xgwm} 181.2-\mathrm{Xgwm} 121$ & 4.8 & 16.4 & -0.06 \\
\hline & & 2 & $7 \mathrm{~B}$ & WMC269.4-WMC338 & 4.3 & 13.4 & -0.03 \\
\hline & $+\mathrm{P}$ & 1 & $5 \mathrm{D}$ & $\overline{\text { Xgwm121-Xgwm292 }}$ & 7.9 & 22.1 & -0.10 \\
\hline \multirow{11}{*}{$\begin{array}{l}\text { SPU } \\
\left(\mathrm{mg} \text { plant }^{-1}\right)\end{array}$} & \multirow[t]{6}{*}{$-\mathrm{P}$} & 2 & $2 \mathrm{~A}$ & WMC382.1-Xgwm636 & 3.7 & 8.9 & -0.05 \\
\hline & & 1 & $4 \mathrm{~A}$ & WMC283.2-WMC262 & 3.3 & 10.9 & -0.07 \\
\hline & & 1 & $4 \mathrm{~B}$ & $\overline{\mathrm{Xgwm} 165.1}$-Xgwm149 & 5.1 & 18.9 & -0.10 \\
\hline & & 2 & $5 \mathrm{~A}$ & Xgwm666.1-Xgwm271.2 & 4.9 & 12.5 & -0.05 \\
\hline & & 2 & $5 \mathrm{D}$ & Xgwm121-Xgwm292 & 8.0 & 21.3 & -0.07 \\
\hline & & 2 & $7 \mathrm{~B}$ & 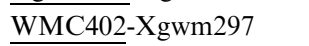 & 4.6 & 11.0 & -0.05 \\
\hline & \multirow[t]{5}{*}{$+\mathrm{P}$} & 1 & $4 \mathrm{~A}$ & $\overline{\text { WMC262-WMC232 }}$ & 4.5 & 12.8 & -0.20 \\
\hline & & 2 & $5 \mathrm{~A}$ & $\overline{\mathrm{Xgwm} 666} .1$-Xgwm271.2 & 4.9 & 16.0 & -0.10 \\
\hline & & 2 & $5 \mathrm{D}$ & Xgwm121-Xgwm292 & 7.7 & 22.0 & -0.12 \\
\hline & & 1 & $5 \mathrm{D}$ & $\overline{\mathrm{Xgwm} 212}-\mathrm{WMC} 215$ & 3.7 & 10.4 & -0.17 \\
\hline & & 2 & $6 \mathrm{D}$ & Xgwm141-Xgdm132 & 3.4 & 8.8 & 0.07 \\
\hline PUE & \multirow[t]{4}{*}{$-\mathrm{P}$} & 2 & $5 \mathrm{~A}$ & $\overline{\mathrm{Xgwm} 666} .1$-Xgwm271.2 & 3.9 & 12.1 & 54 \\
\hline \multirow[t]{8}{*}{$\left(\mathrm{g} \mathrm{SDW} \mathrm{g}^{-1} \mathrm{P}\right)$} & & 2 & $5 \mathrm{~A}$ & Xgdm68-Xgwm156 & 7.1 & 22.9 & 70 \\
\hline & & 1 & $6 \mathrm{~B}$ & WMC486-WMC494 & 4.5 & 18.6 & -54 \\
\hline & & 1 & $7 \mathrm{~A}$ & WMC74.1-WMC116 & 3.9 & 13.0 & -42 \\
\hline & \multirow[t]{5}{*}{$+\mathrm{P}$} & 1 & 3B & $\overline{\text { Xgwm340-Xgwm181 }}$ & 6.4 & 20.4 & 28 \\
\hline & & 2 & $4 \mathrm{~B}$ & $\overline{\mathrm{Xgwm} 251}$-Xgwm6 & 4.0 & 18.9 & 38 \\
\hline & & 2 & $5 \mathrm{~A}$ & $\mathrm{Xgwm} 666.1-\mathrm{Xgwm} 271.2$ & 3.6 & 11.2 & 29 \\
\hline & & 1 & $5 \mathrm{D}$ & Xgwm181.2-Xgwm121 & 4.0 & 11.7 & -22 \\
\hline & & 1 & $6 \mathrm{~A}$ & Xgwm427-WMC247.2 & 4.7 & 18.0 & -26 \\
\hline
\end{tabular}

${ }^{\mathrm{a}} \mathrm{Chr}$ means chromosome name.

${ }^{\mathrm{b}}$ Markers underlined were the nearest marker to the QTL.

${ }^{\mathrm{c}} \mathrm{VE}(\%)$ means variation explained.

${ }^{\mathrm{d}} \mathrm{ADD}$ is abbreviation of additive effects, a negative sign means that the positive alleles come from the parent Lovrin 10 , while a positive sign means positive alleles come from the parent Chinese Spring.

SDW and SPU than that one with the Chinese Spring allele (Table 5). This finding was reproducible under both $-\mathrm{P}$ and $+\mathrm{P}$ condition in both trials (Table 5), indicating that the chromosomal region around $X g w m 121$ may have stable and important influence on P-deficiency tolerance in wheat at seedling stage.

In addition to the locus on chromosome 5D described above, two other chromosomal regions were also found to host multiple QTLs for more 
Table 5. Average increasing effects of Lovrin 10 alleles over Chinese Spring alleles at three significant loci as evaluated in the DH population

\begin{tabular}{|c|c|c|c|c|c|c|c|c|c|c|}
\hline \multirow[t]{3}{*}{ Locus } & \multirow[t]{3}{*}{$\mathrm{Chr}$} & \multirow[t]{3}{*}{ Trial } & \multicolumn{8}{|c|}{ Increasing percentage $(\%)$} \\
\hline & & & \multicolumn{2}{|l|}{$\mathrm{TN}$} & \multicolumn{2}{|c|}{ SDW } & \multicolumn{2}{|l|}{ SPU } & \multicolumn{2}{|l|}{ PUE } \\
\hline & & & $-\mathrm{P}$ & $+\mathrm{P}$ & $-\mathrm{P}$ & $+\mathrm{P}$ & $-\mathrm{P}$ & $+\mathrm{P}$ & $-\mathrm{P}$ & $+\mathrm{P}$ \\
\hline \multirow[t]{2}{*}{ Xgwm251 } & \multirow[t]{2}{*}{$4 B$} & 1 & 45.9 & 30.7 & 17.0 & 15.2 & 18.6 & 14.3 & -0.7 & -0.5 \\
\hline & & 2 & 51.8 & 52.6 & 5.1 & 1.5 & 15.5 & 14.1 & -8.2 & -11.5 \\
\hline \multirow[t]{2}{*}{ Xgwm 271.2} & \multirow[t]{2}{*}{$5 \mathrm{~A}$} & 1 & 21.8 & 7.9 & 9.2 & 8.3 & 12.9 & 13.6 & -3.2 & -4.3 \\
\hline & & 2 & 27.5 & 26.1 & 1.0 & 1.3 & 15.8 & 17.6 & -12.8 & -13.6 \\
\hline \multirow[t]{2}{*}{ Xgwm121 } & \multirow[t]{2}{*}{$5 \mathrm{D}$} & 1 & 29.3 & 33.4 & 27.3 & 33.4 & 17.6 & 25.0 & 9.8 & 7.3 \\
\hline & & 2 & 61.8 & 64.1 & 11.9 & 10.4 & 20.0 & 17.5 & -6.4 & -5.6 \\
\hline
\end{tabular}

Increasing percentages were calculated by comparing the mean values of the investigated traits of the DH lines with Lovrin 10 alleles and that of the DH lines with Chinese Spring alleles at one of the three loci listed in this table.

than one trait. The first one, situated near Xgwm251 on chromosomes 4B, contained one major QTL for TN under -P condition in trial 1 that has been mentioned above and four minor QTLs (controlling SPU under $-\mathrm{P}$ condition in trial 1, TN under $+\mathrm{P}$ condition in trial 1 , and SPU and PUE under $+\mathrm{P}$ condition in trial 2) (Table 4, Figure 1). At this locus the Lovrin 10 allele contributed positively to TN, SDW and SPU, whereas the Chinese Spring allele contributed positively to PUE (Figure 1). Compared to the DHLs with the Chinese Spring allele at marker Xgwm251, those with the Lovrin 10 allele generally had higher TN and SPU in both trials, and higher SDW in trial 1 , under both $-\mathrm{P}$ and $+\mathrm{P}$ condition (Table 5). The second one, associated with $X g w m 271.2$ chromosome 5A, hosted four minor QTLs for SPU and PUE under -P and $+\mathrm{P}$ condition in trial 2 (Figure 1). The SPU QTLs were contributed by Lovrin 10, whereas the PUE QTLs were contributed by Chinese Spring (Figure 1). Although this locus was detected only in trial 2, the DHLs with the Lovrin 10 allele at $X g w m 271.2$ generally had higher TN and SPU than those with the Chinese Spring allele under both $-\mathrm{P}$ and $+\mathrm{P}$ condition in both trials (Table 5). The combined effect of the three loci described above was investigated by dividing the DHLs into two genotypic groups, the Lovrin 10 genotypic group with all Lovrin 10 alleles at the three SSR markers $(X g w m 251, X g w m 271.2$ and $X g w m 121$ on chromosomes 4B, 5A and 5D, respectively) and the Chinese Spring genotypic group with all Chinese Spring alleles at the three corresponding loci. Compared to the Chinese
Spring genotypic group, the Lovrin 10 genotypic group had, averagely, $84 \%$ more TN, $23.5 \%$ higher SDW and $42.5 \%$ higher SPU under -P condition in trial 1 , and $128 \%$ more $\mathrm{TN}, 54.0 \%$ higher SDW and $47.3 \%$ higher SPU under $-\mathrm{P}$ in trial 2.

\section{Discussion}

In this study, efforts have been made to investigate the QTLs for P-deficiency tolerance at wheat seedling stage using the DHLs derived from two parental varieties (Lovrin 10 and Chinese Spring). Lovrin 10 was more tolerant to $\mathrm{P}$ deficiency than Chinese Spring according to the absolute and relative values of SDW and TN in Table 2. This might be related to the fact that Lovrin 10 accumulated more $\mathrm{P}$ in shoot than Chinese Spring under $\mathrm{P}$ deficiency condition (Table 2). However, Chinese Spring had higher PUE than Lovrin 10 under both $-\mathrm{P}$ and $+\mathrm{P}$ condition in both trials (Table 2). In consistent with above differences between the two parents, QTL mapping revealed that Lovrin 10 contributed positively to most loci for TN, SDW and SPU, whereas Chinese Spring 10 contributed positively to most loci for PUE (Table 4).

All the four traits segregated in the $\mathrm{DH}$ population under either $-\mathrm{P}$ or $+\mathrm{P}$ condition (Table 2 ). $\mathrm{P}$ deficiency significantly reduced $\mathrm{TN}$ and SDW of the DHLs (Table 2). However, some DHLs had much higher SDW and TN than other DHLs and their parents under $\mathrm{P}$ deficiency (Table 2), indicating P-deficiency tolerance of wheat may be 
improved through genetic selection and breeding. SPU was more seriously reduced by $\mathrm{P}$ deficiency than SDW and TN under $-\mathrm{P}$ condition, indicating that SPU may be the limiting factor for shoot development during $\mathrm{P}$ deficiency.

Positive correlations were observed in between TN, SDW and SPU, and between SDW and PUE under either $-\mathrm{P}$ or $+\mathrm{P}$ condition (Table 3 ). In consistent with these correlations, positive linkages were observed between QTLs for TN, SDW and SPU on chromosomes 4B, 5A, 5D and 7B, and between QTLs for SDW and PUE on chromosomes 5A and 5D (Figure 1). However, this work did not find coincidence between QTLs for TN and SDW under $-\mathrm{P}$ (Figure 1). This might be explained by the fact that, under $-\mathrm{P}$ condition, only one QTL for SDW was detected in trial 1 (Table 4), and the correlation between TN and SDW was poor in trial 2 (Table 3). Negative correlations were found between PUE and TN, and between PUE and SPU (Table 3). This may offer explanations for the negative linkages between QTLs for TN and PUE on chromosome $4 \mathrm{~B}$, and between QTLs for SPU and PUE on chromosome 5A (Figure 1).

Of the 39 QTLs detected in this study, eight were major QTLs. The locus around Xgwm121 on chromosome 5D contained five major QTLs together with four minor QTLs (Table 4, Figure 1). Furthermore, the most significant QTL for TN, SDW and SPU under either $-\mathrm{P}$ or $+\mathrm{P}$ condition were all mapped around this locus (Table 4). Consequently, this region may have a general importance in controlling shoot development and SPU under $-\mathrm{P}$ and $+\mathrm{P}$ condition. Besides this locus, the locus associated with Xgwm251 on chromosome 4B and the locus with Xgwm271.2 on chromosome 5A may also contribute to the control of shoot development and SPU under $-\mathrm{P}$ and $+\mathrm{P}$ condition. The DHLs with Lovrin 10 allele at Xgwm251, Xgwm271.2 or Xgwm121 generally had higher TN, SDW and SPU than the DHLs with the Chinese Spring allele at the corresponding locus under both $-\mathrm{P}$ and $+\mathrm{P}$ condition (Table 5). The combined effects of the three loci on SPU and shoot development were much greater. These results suggest that the QTLs controlling different aspects of Pdeficiency tolerance may be brought together using MAS to improve plant performance under P-deficiency condition. It was interesting to note that two of the three loci (the chromosome 5D locus represented by Xgwm121, and the chromosome 5A locus represented by Xgwm271.2) were associated with vernalization requirement genes $(V R N-D 1, V R N-A 1)$. The locus for $V R N-A 1$ is approximately $1.9 \mathrm{cM}$ distal of SSR marker Xgwm666 on 5A (http://www.shigen.nig.ac.jp/ wheat/komugi/maps/markerMap.jsp), which closely linked to locus Xgwm271.2 (Figure 1). $V R N-D 1$ is closely linked to SSR markers Xgwm212 and Xgwm292 on chromosome 5D (Snape et al., 2001), which are tightly linked to Xgwm121 (Figure 1). It may not be a mere coincidence that the QTLs for TN, SDW or SPU were closely linked with $V R N$ gene loci. $V R N$ genes are the genetic basis for the classification of winter and spring wheats. Although $V R N$ genes have been found to mainly affect flowering time, they also influence other important morphological traits including tiller number (Kato et al., 2000). Consequently, close linkage between TN QTL and $V R N$ locus under normal growth condition has been reported (Kato et al., 2000; Quarrie et al., 1997). In our study, a QTL for TN under $-\mathrm{P}$ condition and two QTLs for TN under $+\mathrm{P}$ condition were linked with $V R N-D 1$ on $5 \mathrm{D}$ (Figure 1), further confirming the linkage between $\mathrm{TN}$ and $V R N$ genes. It is well known that the number of roots increases in proportion to the number of tillers in wheat. The secondary root system develops simultaneously with the appearance of tillers, the number and branching of roots increase in correlation with the number of tillers (Weaver, 1926). In a hydroponic culture using 120 DHLs derived from winter wheat varieties Hanxuan 10 and Lumai 14, we observed significant positive correlations $(r=0.49-0.59$, $P<0.01)$ between tiller number, root number and root dry weight (unpublished data). The biological implication for the linkages between $V R N$ genes and the QTLs for TN, SDW or SPU under $-\mathrm{P}$ condition may be complex. One hypothesis is that, in winter wheat, the requirement of vernalization may increase tiller formation. The plant with more tillers may possess a more extensive root system. When $\mathrm{P}$ supply is limited, the plant with more tillers and better root system may have higher $P$ uptake and accumulate more dry matter. This implies that it may be easier to obtain P-deficiency tolerant genotypes from winter wheat than from spring wheat. 
In summary, this work has shown that the DH population derived from P-deficiency tolerant variety Lovrin 10 and P-deficiency sensitive variety Chinese Spring is suitable and effective for mapping QTLs related to P-deficiency tolerance at seedling stage. The finding of multiple QTLs for the different traits related to P-deficiency tolerance may reflect the fact that genetic mechanism of $\mathrm{P}$ use in plants is highly complex. The major QTLs revealed in this work may offer valuable clues for further studying such mechanism, and facilitate the development of $\mathrm{P}$ efficient wheat varieties through molecular breeding.

\section{Acknowledgement}

This research was supported by grants (2004CB117200, 2005CB120904, 2003AA207080 and KSCX2-SW-304) from the Ministry of Science and Technology of China, and the Chinese Academy of Sciences.

\section{References}

Basten C J, Weir B S and Zeng Z B 2001 QTL CARTOGRAPHER, Version 1.15. Department of Statistics, North Carolina State University, Raleigh.

Brenchley W E 1929 The phosphate requirement of barley at different periods of growth. Ann. Bot. 43, 89-112.

Gahoonia T S, Nielsen N E and Lyshede O B 1999 Phosphorus (P) acquisition of cereal cultivars in the field at three levels of P fertilization. Plant Soil 211, 269-281.

Gericke W F 1924 The beneficial effect to wheat growth due to depletion of available phosphorus in the culture media. Science 60, 297-298.

Gericke W F 1925 Salt requirements of wheat at different growth phases. Bot. Gazet. 80, 410-425.

Harris G, 1998 An analysis of global fertilizer application rates for major crops by http://www.fertilizer.org/ifa/publicat/ pdf/1998_biblio_18.pdf.

Holford I C R 1997 Soil phosphorus: its measurement, and its uptake by plants. Aust. J. Soil Res. 35, 227-239.

Horst W J, Abdou A G and Wiesler F 1993 Genotypic differences in phosphorus efficiency of wheat. Plant Soil 156, 293-296.

Kato K, Miura H and Sawada S 2000 Mapping Q TLs controlling grain yield and its components on chromosome 5A of wheat. Theor. Appl. Genet. 101, 1114-1121.

Kosambi D D 1944 The estimation of map distances from recombination values. Annu. Eugen. 12, 172-175.

Lander E S and Botstein D 1989 Mapping mendelian factors underlying quantitative traits using RFLP linkage maps. Genetics 121, 185-199.
Li J Y, Liu X D, Zhou W, Sun J H, Tong Y P, Liu W J, Li Z S, Wang P T and Yao S J 1995 Study on the new technology of crop breeding on available utilizing phosphate in soils. Sciences in China (Ser B) 25, 41-48.

Li Y D, Wang Y J, Tong Y P, Gao J G, Zhang J S and Chen S Y 2005 QTL Mapping of phosphorus deficiency tolerance in soybean (Glycine max L. Merr.). Euphytica 142, 137-142.

Li Y J, Liu J Z, Li B, Li J Y and Li Z S 1999a Chromosomal control of the tolerance to soil phosphorus deficiency in genome of common wheat. Chin. J. Genet. 26, 529-538.

Li Y J, Liu J Z, Li B, Li J Y and Li Z S 1999b Chromosomal location of the genes conferring the tolerance to phosphorus deficiency stress in Lophopyrum elongatum genome. Acta Genet. Sinica 26, 703-710.

Liao H, Yan X L, Rubio G, Beebe S E, Blair M W and Lynch J P 2004 Genetic mapping of basal root gravitropism and phosphorus acquisition efficiency in common bean. Funct. Plant Biol. 31, 959-970.

Liu J Z, Li Y J, Tong Y P, Gao J W, Li B, Li J Y and Li Z S 2001 Chromosomal location of genes conferring the tolerance to Pi starvation stress and acid phosphatase (Apase) secretion in the genome of rye (Secale L.). Plant Soil 237, 267-274.

Manske G G B, Ortiz-Monasterio J I, van Ginkel M, Gonzalez R M, Fischer R A, Rajaram S and Vlek P L G 2001 Importance of $\mathrm{P}$ uptake efficiency versus $\mathrm{P}$ utilization for wheat yield in acid and calcareous soils in Mexico. Euro. J. Agron. 14, 261-274.

Manske G G B, Ortiz-Monasterio J I, Van Ginkel M, Gonzalez R M, Rajaram S, Molina E and Vlek P L G 2000 Traits associated with improved P-uptake efficiency in C IM MY T's semidwarf spring bread wheat grown on an acid Andisol in Mexico. Plant Soil 221, 189-204.

Ming F, Zheng X W, Mi G H, He P, Zhu L H and Zhang F S 2000 Identification of quantitative trait loci affecting tolerance to low phosphorus in rice (Oryza Sativa L.). Chin. Sci. Bull. 45, 520-524.

Murphy J R and Riley J P 1962 A modified single solution method for the determination of phosphate in natural waters. Anal. Chem. Acta. 27, 31-36.

Murray M G and Thompson W F 1980 Rapid isolation of highmolecular-weight plant DNA. Nuc. Acids Res. 8, 4321-4325.

Ni J J, Wu P, Senadhira D and Huang N 1998 Mapping Q TLs for phosphorus deficiency tolerance in rice (Oryza sativa L.). Theor. Appl. Genet. 97, 1361-1369.

Osborne L D and Rengel Z 2002 Screening cereals for genotypic variation in efficiency of phosphorus uptake and utilization. Austr. J. Agri. Res. 53, 295-303.

Ozturk L, Eker S, Torun B and Cakmak I 2005 Variation in phosphorus efficiency among 73 bread and durum wheat genotypes grown in a phosphorus-deficient calcareous soil. Plant Soil 269, 69-80.

Pestsova E, Ganal M W and Röder M S 2000 Isolation and mapping of microsatellite markers specific for the $\mathrm{D}$ genome of bread wheat. Genome 43, 689-697.

Quarrie S A, Laurie D A, Zhu J, Lebreton C, Semikhodskii A, Steed A, Witsenboer H and Calestani C 1997 Q TL analysis to study the association between leaf size and abscisic acid accumulation in droughted rice leaves and comparisons across cereals. Plant Mol. Biol. 35, 155-165.

Ouyang J W, Hu H, Chung C C and Tseng C C 1973 Induction of pollen plants from anthers of Triticum aestivum L. cultured in vitro. Sci. Sinica 16, 79-95. 
Röder M S, Korzun V, Wendehake K, Plaschke J, Tixier M H, Leroy P and Ganal M W 1998 A microsatellite map of wheat. Genetics 149, 2007-2023.

Schachtman D P, Reid R J and Ayling S M 1998 Phosphorus Uptake by Plants: From Soil to Cell. Plant Physiol. 116, 447-453.

Snape J W, Sarma R, Quarrie S A, Fish L, Galiba G and Sutka J 2001 Mapping genes for flowering time and frost tolerance in cereals using precise genetic stocks. Euphytica 120, 309-315.

Vance C P, Uhde-Stone C and Allan D L 2003 Phosphorus acquisition and use: critical adaptations by plants for securing a nonrenewable resource. New Phyto. 157, 423-447.

Weaver J E, 1926 Root Development of Field Crops. McGrawHill Book Company, Inc.
Wissuwa M, Yano M and Ae N 1998 Mapping of Q TLs for phosphorus-deficiency tolerance in rice (Oryza sativa L.). Theor. Appl. Genet. 97, 777-783.

Yan X L, Liao H, Beebe S E, Blair M W and Lynch J P 2004 Q TL mapping of root hair and acid exudation traits and their relationship to phosphorus uptake in common bean. Plant Soil 265, 17-29.

Zeng Z B 1994 Precision mapping of quantitative trait loci. Genetics 136, 1457-1468.

Zhu J M, Kaeppler S M and Lynch J P 2005 Mapping of Q TL controlling root hair length in maize (Zea mays L.) under phosphorus deficiency. Plant Soil 270, 299-310.

Section editor: H. Lambers 